\title{
Learning and adaptation from a semiotic perspective
}

\author{
Alin Olteanu \\ University of Tartu \\ Vilnius Gediminas Technical University \\ Kaunas University of Technology \\ Department of Semiotics, Jakobi 2, 51005, Tartu, Estonia \\ e-mail: alin.olteanu@ut.ee
}

\section{Andrew Stables}

\author{
Emeritus Professor, Roehampton University \\ London, United Kingdom \\ e-mail: andrew.stables@icloud.com
}

\begin{abstract}
This paper discusses the relation between learning and adaptation, arguing that the current state of the art in semiotics suggests a continuity between the two. An overview of the relevant theories in this regard, as considered in semiotics, reveals an embodied and environmental account of learning, where language plays an important but nevertheless limited role. Learning and adaptation are seen as inseparable cases of semiotic modelling. Such a construal of these opens up new pathways towards a nondualist philosophy and theory of education.
\end{abstract}

Keywords: learning; adaptation; evolution; exaptation; scaffolding; semiotics

\section{Introduction: Studying learning in relation to adaptation}

Recent research in semiotics, which is reviewed below, has tended to emphasize the need for a reconceptualization of learning in relation to adaptation. More generally, the need for such an investigation stemmed from contemporary views, critical of modern dualist philosophy which contrasts learning to adaptation. In the classic, Enlightenment view, learning was construed as specifically human. More precisely, starting with early empiricism, rationalism and, particularly, contractualism, 
learning has been conceived as the human species' possibility of pulling itself out of a life of strictly biological needs and into a cultural existence. Ever since the contractualism of major modern philosophers such as Locke, Hobbes and Rousseau, educational theory and pedagogy have mostly been developing in view of this assumption. In line with more recent views on knowledge (e.g. Langer 1957[1941]) and embodiment (e.g., Merleau-Ponty 1995; Polanyi 1964; Lakoff, Johnson 1999), we are critical of the anthropocentrism of modern philosophy, addressing this issue particularly in an educational context. While some social sciences have been more eager to consider the swift progress of the natural sciences, leading to disciplines such as ethology and sociobiology, we consider that pedagogy and socio-pedagogy tended to remain loyal to the classic assumptions of modern philosophy. Arguably, the humanities, which feed educational theory and philosophy, have proven particularly conservative and resilient towards a post-Enlightenment view (e.g., Martinelli 2016: 75; Cobley 2017: 9). For instance, (classic) anthropology (e.g. Boas 1938[1911]; Benedict 1934) assumed the understanding of culture of 18th- and 19th-century Romanticism, delivering it further on to the cultural studies of the 20th century, broadly, but now in awareness of Darwinism. Stjernfelt (2011) and Eriksen and Stjernfelt (2010, 2012) developed a thorough criticism of the mainstream theory of culture in classic anthropology, as received from German Romanticism. Particularly, the conservatism of educational studies blocks the development of an ecological concept of learning. Learning, we argue, should rather be conceived of in awareness of the environmental dimension of knowledge or, more broadly, the interconnectedness of epistemology and ecology.

In one of the not many efforts to systematically establish a complete theory of biosemiotics, Favareau (2010b: 3) sets as starting question a sharp critique of a historically enduring temptation of philosophy which seduced modernity: "How did modern science - the communal knowledge-generating system par excellence - arrive at this sterile impasse - one where the investigation of individual knowledge-generating systems as knowledge-generating systems per se has come to be seen, at best, as a vexingly paradoxical riddle and, at worst, as falling entirely outside the scope of legitimate scientific inquiry?" Approximately half a century before Favareau's semiotic inquiry, Michael Polanyi had already placed the core of this problem on the agenda of phenomenological and embodied approaches to knowledge. Polanyi (1964: 6) considered that "all knowledge is acquired by indwelling". This endorses the view that knowledge has a tacit aspect which escapes formal teaching and which any learner must discover on her own. In view of the modern construals of reason and knowledge, the teacher is meant to simply deliver to, or, at best, scaffold (e.g., Bruner 1957, 1990[1960], 1966) knowledge (in the 
form of curricular subjects and topics) for the student. This also implies that the student's knowledge can be assessed as relative to that of a supposedly objective curriculum, expressed in a scientifically accepted form, or to that of the teacher (for a semiotic, qualitative criticism of this view see Olteanu et al. 2015).

By discussing learning $v i s-\grave{a}$-vis adaptation from a semiotic perspective, the present paper aims to offer solutions for educational theory and philosophy, given the educational impasse resulting from the epistemological impasse discussed by Favareau. Like Favareau, we consider that the key to overcoming this sterility experienced lately in science in general, but particularly in the humanities, stands in a unified theory of biology and meaning, namely "a semiotic paradigm for biology which considers that the biological form should be understood first and foremost as a sign" (Lestel 2011[2002]: 388). If forms carry meanings it does not mean that form and meaning can be separated, in a Cartesian drive of clearly distinguishing one concept from another, or in the Saussurean fashion of differentiating between the signifier and the signified. Neither can any form be conventionally attributed any meaning, as the (so-called) arbitrariness hypothesis would claim. Biology accounts for a spectrum of meanings that a form affords within the horizon of an organism's competences for meaning-making. This spectrum is a biology-aware account of the Vygotskian zone of proximal development (see Vygotsky 1978: 84-85). Hoffmeyer terms this 'semiome', in addition to the notion of genome. He claims that:

Evolution is primarily about the establishment of successful semiotic scaffolding devices, and genetic mutations are just elementary tools in this process that may often not rely on modifications at the genetic level at all. The genome thus is only half the story, the other half being the semiome, the entirety of semiotic tool sets available to the species: the means by which the organisms of a species may extract significant content from their surroundings and engage in intra- or interspecific communicative behaviour (Hoffmeyer 2014). The semiome defines the scope of the organism's cognitive and communicative activity. (Hoffmeyer 2015: 9)

To understand Hoffmeyer's claim one must keep in mind that semiosic activity (in line with Peirce's definition of semiosis, CP 5.484) should not be confounded with, but is a prerequisite for cognition (see also Hoffmeyer, Stjernfelt 2016: $8,15)$. What falls outside the design possibilities of such spectra, as described above, should not be considered learning (in an educational concern) but, at best, mechanical repetition (reiteration). A student, for instance, might perform in a way that convinces the teacher that the student has truly understood the subject matter. However, the teacher cannot tell if what the student actually learned is the subject matter or only how to simulate its apprehension (for a discussion on some 
implications for education of a biosemiotic account of scaffolding see Olteanu et al. 2015). In Polanyi's terms, the teacher might well have access to a distal term that the student exposes, but has hardly any evidence for the proximal term of the student's tacit knowledge.

Thus, in what regards learning, consideration should be given to the role of the body for how it makes meaning articulation possible, while also confining it. According to Stjernfelt (2006) structuralism has established the tradition in semiotics of regarding the body as but another concept of language, pointing out the variance of representations of the human body across cultures and, thus, to the conventionalism involved even in understanding physiology. This subjects the body, and its role for the modelling of subjective environments, to the arbitrariness of meaning-form articulations, as supposed in the structuralist school. Instead, Stjernfelt (2006: 14) argues in favour of seeing "the body as a crucial prerequisite of semiotic articulation".

\section{Criticism of modern philosophy of education}

Favareau (2010b: 3 ) notices that while the instinctive starting point of the investigation which his question invites is René Descartes, the ontological demarcation in philosophy of matter and mind started long before. Along this long history of ontological dualism, which became the mainstream with Locke and Descartes, in the view of, among others, Donald Favareau (2010a) and John Deely (e.g., 2001), a non-dichotomic philosophical tradition also endured. This tradition is identified with the rediscovery of the concept of sign by Charles Peirce, by Ferdinand de Saussure in a linguistic context ${ }^{1}$, and by Jakob von Uexküll in a biological context. In an educational regard, for now, the focus of such critique is justified to address mainly the post-Cartesian, Enlightenment inheritance. More than other branches of theoretical philosophy, educational philosophy but also educational practice (schooling) remain anchored in the claims of modern

1 Caution should be taken in attributing the arbitrariness hypothesis primarily to de Saussure. First, de Saussure limited his discussion to linguistic signs. The arbitrariness hypothesis mostly implies a sterile construal of learning as strictly conventional, symbolic calculus when applied to knowledge in general, not so much to language specifically. Second, the idea was both already present, albeit not explicitly, in cultural and linguistic theories and was extrapolated further on by structuralist philosophy's (e.g. Derrida's (1978[1967], 1981) insistence on the relation of opposition and his notion of 'différance'), from de Saussure's linguistic concern to knowledge in general. Also, some credit must be given to some Saussurean-inspired semiotics for attempting to undermine body/mind dualism (e.g. Deleuze, Guattari 1987[1980]; Lotman 1977, 1990). 
dualism. The modern view of learning as strictly human has also consolidated a rigid account of adaptation, in strictly a Darwinist sense. The main problem that arises for education, not from the Darwinian theory of evolution, but from its uptake in a substance dualist philosophical frame, is that it makes adaptive strategies seem unintelligent or, so to say, brute physical changes caused by merely material factors (see Gough, Stables 2012: 371-372). This notion supposes that adaptations are strictly biological, occurring slowly, over generations, and that the individual organism or community has no control over them and their implications. In this view, adaptation refers to long-term and collective changes while learning usually refers to short-term changes in an individual. However, in everyday speech the word 'adapt' is insightfully used more loosely, covering a wider spectrum of situations. For instance, immigrants and refugees are required to 'adapt' to new cultural contexts, pupils 'adapt' to a new school, newlyweds 'adapt' to the married life and so on.

Certain hypotheses in biosemiotics come in defense of the everyday speech use. According to Sharov et al. (2015: 361), biosemiotics differs from previous semiotic theories, focused on cultural signification, by considering "the dynamics of semiosis at multiple time scales, and emphasizes the active role organisms have in reshaping sign relations". Considering the evolution of meaning as the same type of phenomenon regardless of the timescale already suggests the need for bridging the classic adaptation/learning dichotomy. More of a fluidity of these two concepts is assumed in this view not only because of a more general understanding of 'adaptation', but also of 'learning. For instance, Stjernfelt (2012, $2014,2015)$ exposes a view according to which evolution itself learns. Namely, evolution learns to adapt (more efficiently) to structures of signification. Stjernfelt considers that the biology of organisms became more complex as organisms begot more fine-tuned competences for dissecting complex semiotic structures into more simple composing parts (e.g. arguments into propositions, propositions into subjects and predicates, predicates into icons and so on). Thus, he explains that "semiotic evolution rather takes the shape of the ongoing subdivision, articulation, and sophistication of primitive signs, an ongoing refinement of parts and aspects acquiring still more autonomy" (Stjernfelt 2012: 47). This is because the environment presents structures "which evolution as well as development are forced to adapt to" (Stjernfelt 2012: 40).

In this paper we advocate for the loosening of the concepts of adaptation and learning (at least) as used in education studies, by way of this semiotic framework. This leads to a general better understanding of their continuity. Consequently, we hope that this construal of learning will draw the attention of education studies towards semiotics. 
It is in light of its entailed theory of modelling that we consider that semiotics can revitalize educational theory and philosophy. To begin with, most of the contemporary acknowledged semiotic theories dismiss the dichotomical tension between learning, in a strictly cultural sense, and adaptation, in a strictly biological and physiological sense. The (relatively) recent development of biosemiotics suggests a turn in representation theories in general towards biocentrism and away from anthropocentrism (see Martinelli 2010: 318-325). This is to say that there is meaning widely in nature, not only in the rather narrow human semiosphere, which, taking over the global ecosystem, becomes an Anthropocene. The cornerstone that biosemiotics holds in this regard is its overarching use of the Peircean concept of semiosis, which during most of the 20th century has been used to discuss only cultural and social change (e.g. Eco 1976). Sharov et al. (2016: 2) explain that biosemiotics "considers that evolution is semiosis, a process of continuous interpretation and re-interpretation of hereditary signs alongside other signs that originate in the environment or the body". While the adaptation/ learning dichotomy particularly has been seldom addressed explicitly, many of its supporting dichotomies, such as, to begin with, individual/collectivity, and also agent/subject, verbal/nonverbal, human/non-human, matter/mind, living nature/ culture, have been discussed and dismissed in biosemiotics (e.g. Cobley 2010, 2016). By this it is not implied that these notions are not distinct, but that they can be formulated in a relation other than dichotomous, which proves more insightful and adequate for current epistemological demands.

Moreover, the acceptance or dismissal of the modern polarized worldview has direct implications for learning. Cobley (2016: 126) mentions that, from a biosemiotic perspective, "not only are the binaries false oppositions but the human Umwelt, characterized by its constant drive to expand its range, should not allow such binaries to hinder its enrichment". For this consideration, Cobley finds inspiration in Charles Peirce's dictum, "Do not block the way of inquiry" (CP 1.135), following the latter's idea that, like reality, knowledge is continuous. Umwelt, or the subjective environment of an organism, is the model by which the organism knows its own world phenomenally. This concept, originating in Jakob von Uexküll's (1926) theoretical biology and adopted in semiotics via the works of Thomas Sebeok (see 1991, 2001a[1994]), brings together adaptation and learning as forms of interpretation by which models of the world are constructed and refined. According to von Uexküll, umwelt (environment) is a functional cycle (or circle, Funktionkreis) of perception and action signs (see Uexküll 2010[1934]: 49). Loops of such signs account for a world populated by subjective meaning-carriers, rather than objective entities that present to the perceiving organism nothing other than their immediate presence. On this account, an element of subjectivity 
is justified in scientific inquiry, as knowledge itself belongs to embodied organisms that cannot be otherwise than subjective.

Thus, the need for redefining learning in relation to adaptation was mainly observed in semiotics in two ways: not only (1) within the developing semiotic research on education, loosely termed edusemiotics (see Semetsky 2010; Olteanu 2015; Stables, Semetsky 2015) but, also, (2) in biosemiotics, the semiotic theory of biological modelling.

\section{Learning results in change}

We advance a notion of learning as change that is seen as significant. Learning always changes us in some way and the everyday use of the term 'adaptation' is not far from this understanding of learning. By contrast, Darwin's conception of adaptation is too narrow for claiming that all learning produces (Darwinian) species adaptation. Rather, we argue, in addition to the post-darwinian realization that epigenetics stops genetically identical individuals from being actually identical, there always is a certain scope for freedom of action within a biologically determined organism. Any embodied organism is equipped with some semiotic competences, stemming from the morphology of the body itself, which render the organism a corresponding (semiotic) freedom (Stjernfelt 2006). This is a semiotic validation of what is termed the Baldwin effect, namely the idea that learning enhances evolution (Baldwin 1896, see also Hoffmeyer, Kull 2003). Thus, we consider that biology needs to examine the concept of adaptation in the context of tool use generally and, particularly, of media changes (specifically digitization, for contemporary concerns) and advanced science (e.g., prosthetics). At the same time, educationalists need to get used to the idea that 'learning' cannot validly be seen as a purely cognitive, mental process unconnected to physical change. Every experience/event is a (sort of) utterance written onto, into and by the body, as already evidenced by Stjernfelt (2014) in a bio- and cognitive-semiotic framework.

In a recent discussion on education, and in the effort of developing a semiotic theory of education, Gough and Stables (2012) straightforwardly approached this topic, arguing that interpretation can be construed as a case of adaptation. In general, semiotics regards learning as a matter of interpretation. Learning is a hermeneutical endeavour. Gough and Stables' argument proved particularly insightful, as, even though recent, by the time of its publication, semiotic research on education had not yet manifestly discovered its affinities with biosemiotics. Since Thomas Sebeok's pioneering research (e.g. Sebeok 1991, 2001a), the semiotic 
theory of biology (biosemiotics) has been founded on the premise that speech, as manifest in Homo sapiens, evolved as an exaptation, accidentally possible due to certain previous adaptations. The hypothesis of speech as the result of an exaptation holds that existing, typically mammalian, features for respiration and ingestion were made use of by Homo erectus, in a way that they were probably not designed for, namely for producing phonemes (see MacLarnon 2012: 225). Thus, the modern human being, with its specific capacity for culture and technology, is not possible due to a mutation that proved useful, but due to an innovative use of physiological features that had developed for different purposes. That speech resulted and was developed beginning from an exaptation, and not an adaptation in the Darwinian sense, means that the development of speech was not inevitable, but it was a physiological possibility that was made use of when environmental conditions favoured it. By environmental we mean not only external physical conditions, but the organism-context signifying relations, or umwelt, in Uexküllian terminology. Such an exaptation, of course, changes the species' environment (umwelt) in its own turn.

Vocal communication has proven highly efficient and constitutes a considerable survival advantage of humans. More than merely for survival, over time, vocal communication in the form of speech has profound hermeneutical consequences. The re-modelling of the environment that speech produced in humans, however, does not overrule previously existing modelling competences. Rather, it adds to them. Perhaps it remodels, it fine-tunes, previously existing modelling competences, but it does not plunge the human species into an altogether different reality, detached from the natural, biological world. The primary, pre-existing modelling competences of humans are nonverbal and, as the exaptative emergence of speech suggests, verbal but not vocal. According to Stjernfelt the reason for the adaptive success of speech is that it offers a finer grasp and use of Subject-Predicate structures, which are essential for survival and for navigating the environment. In light of Peirce's sign taxonomy, Stjernfelt argues that speech highly facilitated a use of propositions in their linguistic form, which is more precise and renders a higher semiotic control than the more wobbly use of what can be called protopropositions. The latter are signs consisting of a dual structure composed of (1) an index and (2) an icon describing the index qualitatively (Hoffmeyer, Stjernfelt 2016: 26; see also Stjernfelt 2014: 144). This argument, of course, stands only in view of the notion of semiosis as not dependent upon cognition, like in the case of Hoffmeyer's argument for the semiome defining the scope of cognition and communication. Moreover, Stjernfelt explains that neither does the presence of semiosis imply consciousness, a position which should be most attractive for 
philosophy, as it avoids the ever perilous and often dualism-endorsing discussions on this topic ${ }^{2}$ :

\begin{abstract}
Signs which may not convey truth are hardly efficient in biology: isolated icons only indicating vague possibilities have little if any pragmatic efficiency in cognition and communication, just like isolated indices only able to indicate that something is happening at a location but not what it is, may be of restricted, local use but not much more than that. This is why Dicisigns ${ }^{3}$ are ubiquitous in biology. This may seem hard for both biologists and biosemioticians to appreciate, probably because of the widespread idea that propositions require judgement of a conscious "propositional stance" found only in human beings as well as the whole of the machinery of human language to express those propositions. Here, Peirce's purely semiotic definition of the proposition as a Dicisign combining two signs into one irreducible whole gives us a formal notion of Dicisign - neither presupposing consciousness nor explicit acts of judging. (Stjernfelt 2014: 144)
\end{abstract}

The exaptation hypothesis regarding speech also demystifies the supposed overwhelming consequences of writing. Stjernfelt's theory of natural propositions is supported as well by this hypothesis, as it explains that the rationale behind the emergence and development of spoken language is the communication of existing models of existing structures. From the (bio)semiotic point of view, where environments are the result of modelling and, thus, are models, writing and speech stem from the same modelling system and are both developed in view of the same function. That is to say, writing is speech which is not verbally, but visually reproduced. Both speech and writing are thus labelled to belong to the secondary level of modelling systems. Secondary modelling systems have the peculiar feature of functioning monomodally: while speech does not require visualization, writing does not require hearing. Each entails another characteristic, further on, which can be an advantage or disadvantage, according to context: speech disappears in a short

2 However, in their semiotic approach to evolution, Hoffmeyer and Stjernfelt (2016) still pursue and argue for a notion of (self-)consciousness, as a late and advanced evolutionary development requiring cognition. We consider that this discussion of what after all is an empirically non-verifiable concept, namely consciousness, could be avoided.

3 'Dicisign' or 'Dicent Sign' is Peirce's general concept of a general proposition, encompassing of sensory modalities. In Peirce's taxonomy it is situated as the sign that describes its Interpretant in relation to its Object: "A Dicent Sign is a Sign, which, for its Interpretant, is a Sign of actual existence. It cannot, therefore, be an Icon, which affords no ground for an interpretation of it as referring to actual existence. A Dicisign necessarily involves, as a part of it, a Rheme, to describe the fact which it is interpreted as indicating. But this is a peculiar kind of Rheme; and while it is essential to the Dicisign, it by no means constitutes it" (CP 2.251). 
span of time and the one who produces it can remain hidden to agents to which it wants to remain hidden, while writing remains perceivable for a longer period of time, which means that it can be produced and still communicate at a later date, being also efficient for recording.

This is important to acknowledge in education, as the modern educational paradigm, of which we here develop a criticism, tended to consider writing systems as a feature that empowers human education all the more, proving the detachment from the bio- and zoo-sphere of the human species. Reading and writing are the first skills to be taught in schooling. Thus, as even the word itself suggests, literacy mainly consists in reading and writing skills. From a biosemiotic perspective, the basic skills for surviving and thriving in society should consist in ways of understanding the environment that evoke semiotic resources. The conceptualization of speech and writing as altogether different linguistic systems was explicitly stated by de Saussure (1959 [1916]: 23-24) and further exploited in linguistics in general, particularly in functional linguistics (Martinet 1962: 59), which has since determined to a large extent the course of research in phonetics and phonology (see Akamatsu 2009). However, as seen in the study of phonetics and phonology, a new critical direction emerges once with the hypothesis that spoken language resulted from exaptation (Gould, Vrba 1982; see also MacLarnon 2012 and more below).

That speech and vocal (as well as written) language became possible because of evolutionary features occurring for reasons other than linguistic communication is critical for how we conceive human knowledge and behaviour. It allowed Sebeok to argue that these are not primarily dependent on linguistic classification. Sebeok adopted the semiotic modelling theory of Juri Lotman (e.g. Lotman 1977), albeit contributing to it with a major revision, namely that humans have three, not two, modelling systems. To the linguistic and the supra-linguistic (cultural, scientific etc.) modelling systems supposed by Lotman, Sebeok added a non-linguistic modelling system, which, in view of the exaptation hypothesis, is prior to the others: "A concept of 'modelling systems' has been central to the semiotics of the so-called Moscow-Tartu school since the 1960s, but, having been derived from a representation of language in structural linguistics, it focused on culture to the exclusion of the rest of nature" (Sebeok 2001a: 26-27).

\section{Learning is not only linguistic}

Sebeok remarked that communication and linguistic theories cannot make abstraction of nonverbal communication, which is much more spread in nature 
than verbal communication, the latter being quite specific to humans (e.g., Sebeok 2001b). Learning, it is important to mention, is not specifically human. While we agree with Sebeok, we also point out the insight that common parlance suggests. It is a biological truth that modelling systems based on the verbal modality require the pre-existence of nonverbal modelling systems. To Sebeok's foundation of biosemiotics, we add the observation that 'adaptation' is used in everyday speech to refer to changes in form and behaviour as the result of changed responses to environment. On this account, adaptation is a sort of sustained change, which qualifies it as a tendency or habit, on a Peircean account. However, in Darwinian biology, adaptation refers to physical changes within species that take place slowly, through generations. Exaptation itself is a form of adaptation, in the loose, everyday speech sense. Following Dennett (1996), in view of the coevolution school(s) of language evolution, Scalia (2019: 96) argues the other way around, namely that "all adaptation is exaptation" as an adaptation opens up new (accidental) modelling possibilities. While worded vice versa, Scalia's hypothesis is compatible with the present argument that exaptation is a form of adaptation. Both of these theories account that, for instance, brain plasticity and kinesio-semiotic competencies are mutually dependent (see Scalia 2019: 99).

Exaptation is a different phenomenon than the Darwinian account of adaptation, or at least as it has been perpetrated in neo-Darwinism. This strictly Darwinian and biologically evolutionary notion of adaptation is not aligned with the biosemiotic view on evolution, (partly) inspired from Peirce's theory of evolution (CP 1.103-1.109, 6.287-6.317). On this Darwinian account, all change to an individual does not count as adaptation. Some more recent theories of evolution and ecology come in support of the popular understanding of 'adaptation'. For instance, Bateson's account (Bateson 1972) of systems theory differentiates between phenotypical and genotypical changes (other work distinguishes between genetics and epigenetics) and also between temporary and enduring changes. That is, every individual has a certain level of adaptability (in the everyday sense) or "wriggle room" to respond to everyday challenges, but this level of adaptability is constrained by genetic make-up and epigenetics (which genes are active within the individual). Thus, adaptation in the Darwinian, species sense, sets the parameters for individual adaptability on the day-to-day level.

If all biological organisms have an embodied, non-linguistic modelling system, as according to Sebeok (2001b: 14), it can be inferred that all organisms make sense of their environment(s) as according to the meaning-making competences that their embodied morphology affords. Stjernfelt (2006) discussed this implication of biosemiotics. Also, from an embodied and cognitive semiotics point of view, Pelkey argues that the relevance of X-patterns (chiasmus) for meaning-making in 
humans stems from our body's morphology (Pelkey 2017). The correlation between embodied morphology and meaning has profound consequences for learning, contradicting not only mind/body Cartesianism but also the anthropocentric notions of learning and of education which dominated Western philosophy and pedagogy (at least) starting with the Enlightenment (see also Scalia 2019: 92 and Olteanu 2018). To begin with, that a physiology which affords speech production developed speech, as an exaptation, and led to the evolution from Homo erectus to Homo sapiens, blurs the supposed delineation between biological adaptation and cultural learning. This example illustrates a capacity in hominid species of creatively and purposefully using an accidental semiotic resource, leading to the development of new semiotic competences. By no means does it exclude creativity in other species, of course. It is difficult to overestimate the consequences of this semiotic competence, which go beyond the immediate purpose of those hominids who started using it and developed (the first elements of) verbal language. The process is neither strictly biological, nor strictly cultural. The biological and the cultural and the individual and the collective aspects are inseparable in an environmental modelling with complex consequences. Herein is noticeable how a (fully) semiotic account of adaptation is in contradiction with the classic Darwinian one.

Starting from Sebeok's consideration that the "strategic anthroposemiotics/ zoosemiotics dichotomy will stand, just as long as the riddle of the origin of human language remains unsolved" (Sebeok 1985: 299), Scalia (2019: 90) argues that a semiotic framework for studying the evolution of language can unify the otherwise scattered puzzle pieces that various disciplines have unravelled on this matter. The main argument that Scalia brings in favour of a semiotic theory of language evolution, inherited from Sebeok, is the supposition of the continuity of meaning throughout the biosphere (an idea, in turn, inherited from Peirce, as discussed below). Thus, from this perspective, language is studied within the overall complexity of a semiobiosphere.

\section{Exaptation as a sub-case of adaptation}

From a Darwinian perspective (Darwin 2008[1859]) adaptation to environment is regarded in very much observable physical structural terms (e.g., growing new limbs, such as wings, or becoming smaller or bigger, over many generations). On this account, adaptation does not encompass the potentially long-term changes brought about in humans (at least) through changed environmental interactions, such as occur, for instance, via technology. For example, we have adapted to air 
travel, but not by changing hands to wings; rather, we have invented aeroplanes. Now, this will have changed the human species in some way, but not necessarily in terms of observable physical structure. Nevertheless, the consequences over very long periods of time of humans' adaptation (or exaptation) to flight are impossible to overestimate. Not only did air travel lead to different social organizations, with everything that these entail, but (like other similar examples) it is also an important step from the environmental transformation from holocene to anthropocene (Crutzen, Stoermer 2000; see Steffen et al. 2011; Rockström et al. 2009). It might also prove (like other similar examples) very useful in the attempt to come closer to the environmental balance of the holocene. Like any use of semiotic competences, it simultaneously evokes new semiotic resources and possibilities while also obstructing others. While burning fuel, air travel might arguably have uses for ecological purposes. Another consideration is that while flight did not produce observable physical changes in humans, it is not impossible that, over time, it might. It is not to be excluded that the habit of air travel, over generations, might lead to growing physically weaker, as our backs may be adapting to sitting, and even to impacting on our brain biology and chemistry. These could only be speculations for now, but they find abductive justification in evolutionary theories.

Sebeok's theory is not dismissive of the profound changes that exaptations (can) have. From a biosemiotic perspective, language plays an important role in knowledge acquisition. The emergence of language is, to begin with, considered an evolutionary phenomenon because, by its efficiency to communicate complex meaning structures, it allows for and implies new modelling capacities. Language also proves of great pragmatic value. As discussed above, it is very efficient at representing subject-predicate structures (propositions). These are complex meaning structures, the use of which is critical for the survival of any animals and possibly also some plants and bacteria (see Stjernfelt 2014:144; Hoffmeyer, Stjernfelt 2016: 16), because of their pivotal role in both the development of syllogistic arguments and the identification of simpler, composing sign-relations, such as indexes and predicates, from which factual information can be derived.

It is most relevant that, from its beginning, biosemiotics was defined by Sebeok (e.g. 1991, 2001a) as a modelling theory and, while useful for cognitive theories as well, it does not impose any particular assumption about cognition. Thus, from this perspective, a theory of learning does not necessarily imply a discussion on cognition. An educational theory and system can conceive learning in terms of signification only. This might prove useful because it raises awareness of the freedom of individuals to learn, regardless of limitations supposed because of cognitive capacities, social power relations or economic situation. Learning is interpreting: by learning something, a knowing subject remodels her environment 
as she discovers new sign-relations. Rather than being limited by cognitive capacities and socio-economic status, learning is better understood as limited by environmental relations. The environment presents semiotic resources according to the way in which an organism relates to it. As such, what limits learning coincides with what makes it possible, namely the organism's interpretative framework, understood phenomenologically, as explained elsewhere by Stables (2012: 46). In this view, learning is ecological, always dependent on organism-environment relations. Thus, such a semiotic theory of learning is akin to the idea of human activity proceeding within the frame of ecological constraints, such as planetary boundaries (Rockström et al. 2009).

The potential semiotic resources, however, are enormous, if not infinite, at least for higher biological organisms, with complex cognitive systems. Social, economic, cultural and even cognitive features are only learning parameters within the greater environmental picture, if the environment is to be understood in a suprasubjective (borrowing this term from Deely 2001) sense, encompassing both the biological and the cultural, in virtue of the continuity of signification throughout these spheres. The limitation of each of these parameters can be, to a large degree, supplemented and overcome by the use of others. The discovery of semiotic resources, according to semiotic competences, produces, in turn, new semiotic competences. Thus, creativity is understood neither as strictly a cognitive feature nor as entirely dependent on the individual or on environmental circumstance. It is rather easy to agree that Einstein, Picasso and Maradona were all creative but discovered and used different semiotic resources, modelling their environments differently. To claim that one of these is "more intelligent" than the others reflects a rigid modern understanding of "intelligence", often construed as dependent on reason in a (post-) Cartesian sense.

With his biosemiotic project Sebeok intended to explain modelling in the biosphere in terms of phenomena of signification. This intention is justified by (what is now called) the Sebeok hypothesis, namely that life and meaning are coextensive. Meaning is continuous throughout the biosphere. Sebeok found this idea expressed in two theories of the late 19th and early 20th centuries, namely the semiotic logic of Charles Peirce (e.g. CP 6.272-6.286) and the theoretical biology of Jakob von Uexküll (e.g. 1926, 2010[1934, 1940]). Charles Peirce considered that a doctrine of continuity must be the cornerstone of pragmatism, a philosophical project that he conceived as overcoming ontological dualism (CP 5.415). He named this doctrine 'synechism' (CP 6.169). Further on, upon his maxim of pragmatism (e.g., CP 5.438), Peirce developed a theory of logic expressed in terms of signs. Signification, thus, appears as the continuous phenomenon (or set(s) of phenomena) that, as it were, glues reality together. Similarly, in a biological 
concern, von Uexküll's theory acknowledges that in the biosphere, ecosystems and individual organisms' life-worlds are not separated from one another, as elements of a discrete set. This led Sebeok to explain that Uexküll's concept of environment (umwelt, as coined in the original German) is a model which more than merely constituting organisms' understandings of their phenomenality, also constitutes organisms' means of communicating:

All organisms communicate by use of models (umwelts, or self-worlds, each according to its species-specific sense organs), from the simplest representations of manoeuvres of approach and withdrawal to the most sophisticated cosmic theories of Newton and Einstein. (Sebeok 2001a: 23)

As Stables (2012) recently explained, an epistemological advantage of contemporary semiotics is its means of easily accounting for the overlapping of phenomenal worlds. This idea is present in von Uexküll's theoretical biology as well: "The function-circles of the various animals connect up with one another in the most various ways, and together form the function-world of living organisms, within which plants are included" (Uexküll 1926: 126). ${ }^{4}$

The precise number and layering of modelling systems that humans or other species (in comparison) master is not our concern here. What is important is the hypothesis that all organisms model their environment and that language, while a powerful modelling system, does not and cannot overwrite how the human animal, given its pre-linguistic modelling competencies and affordances, understands its environment. The modelling capacities of any animal relate to a basic internal model that could not be verbal or, for that matter, of any acquired modality: "The Innenwelt of every animal comprises a model [...] that is made up of an elementary array of several types of nonverbal signs [...]" (Sebeok 2001a[1994]: 145).

In awareness of this, semiotics offers a bridge between the humanities in general, and the natural sciences. This could well be a way out of the crisis that the humanities have been recently facing (regarding the crisis of the humanities see Nussbaum 2010 and Martinelli 2016, and for how biosemiotics can tackle the crisis see Cobley 2017).

Sebeok's adoption of the exaptation hypothesis (see Sebeok 1991: 56) is grounded in the same study that established it in the natural sciences and in

4 The authors are aware that this English translation of von Uexküll's Theoretische Biologie received some criticism and, also, that the German word 'Funktionskreis' does not have a straightforward translation to English. However, to this date there is no unanimously accepted English translation of this book. Also, we consider that for the limited purpose of this article, the translation is acceptable. 
evolutionary anthropology, namely the celebrated article of Gould and Vrba (1982). Gould and Vrba, as well, justified the need for a concept of exaptation by starting from a taxonomical confusion caused by the unclear delimitation of adaptation in a strictly Darwinian sense and in its vernacular use (Gould, Vrba 1982: 4-5). Thus, to retain a strictly Darwinian use of the 'adaptation' term in evolutionary biology, they proposed the term 'exaptation' to refer to "features of organisms" which are "non-adapted, but available for useful cooptation in descendants" (Gould, Vrba 1982: 4). Such features, they argue, "enhance fitness but were not built by natural selection for their current role" (Gould, Vrba 1982: 4). As mentioned, and as received by Sebeok, we agree with the conceptual difference between Darwinian adaptation and exaptation but, particularly in light of more recent research in biosemiotics (e.g., Hoffmeyer 2015; Hoffmeyer, Stjernfelt 2016; see Sharov et al. 2015, 2016), we argue for the need of expanding the sense of the terms 'adaptation' and 'learning', in view of eliminating the dichotomy. Actually, the difference between adaptation and exaptation is necessary for an accurate and adequate notion of learning as ecological. The key stands in seeing exaptation as a semiosic sub-case of adaptation, in a broad sense. This idea is already suggested by Hoffmeyer's semiotic version of the idea of knowledge acquisition as 'scaffolding' (Hoffmeyer 2006, 2015; Hoffmeyer, Stjernfelt 2016; see also Kull 2015 and Olteanu, Campbell 2018: 253-254), or, as similarly expressed by Kleisner (2015), 'semiotic co-option'.

While evolutionary anthropology (e.g., MacLarnon 2012) advanced and eagerly accepted the hypothesis of language as exaptated, cultural and communication studies generally developed in ignorance of this, favouring the epistemological language-centredness of 20th-century philosophy and linguistics. In this view, language and speech have been misconstrued as an inevitable biological hardwiring of humans (or, specifically, of Homo sapiens), which places this species on an altogether different existential plane than the rest of the animal realm. Mainstream cultural anthropology (see Eriksen, Stjernfelt 2012: 134, Cobley 2016: 18) and sociolinguistics (see Randviir, Cobley 2010: 119) are included here. For instance, Elleström $(2018,2019)$ recently noticed that communication studies are in want of a communication model that, first of all, takes into consideration non-verbal communication, and, subsequently, does so not in analogy to the verbal. While this pertinent claim was convincingly argued for only recently, Sebeok included this awareness as a founding rationale of biosemiotics almost half a century ago. Thus, biosemiotic theory can deliver the exaptation hypothesis, together with a full-blown modelling theory, to the vast area of communication studies. As regards cultural studies, Cobley $(2010,2016)$ opened the avenue for a non-dualist and nonanthropocentric framework, by recommending a biosemiotic approach, whereby 
"human affairs", inclusive of all human culture, "are sought in the interrogation of modelling" (Cobley 2016: 28).

\section{Learning as semiotically embodied}

In view of these considerations, a theory of learning has to take into account those ecological relations that render semiotic resources and competences for modelling, that is, "a body concept which entails semiotics" (Stjernfelt 2006: 14). The need for a semiotic notion of the body and its implications have been discussed by Stjernfelt (2006) and Hoffmeyer (2008). From this perspective, a correspondence between semiotic competences and behaviour is claimed, accounting for an only partial and limited (re)modelling produced by languaged-behaviour. The concept of competence has been widely debated in education studies (e.g., Barnett 1994; Westera 2001; Mulder et al. 2009). Recently, Pikkarainen (2014) discussed the implications for education of a semiotic concept of competence (see also Pikkarainen's article in this issue). ${ }^{5}$

The concept of semiotic competence seems to have initially emerged from that of literary competence (see Culler 1980: 109-110), stemming from Chomskyan (Chomsky 1965) and Saussurean linguistics. These accounts of linguistic competence neither take into consideration the body's role in learning nor are they concerned with the subjective process of learners' acquisition of concepts. Nöth observes that, like Greimas and Courtés' (1982[1979]) notion of semio-narrative structures and de Saussure's 'langue', Chomsky's notion of competence underpins a fundamental grammar (Nöth 1995: 315-316). This concept of competence is an intrinsic characteristic of language itself rather than descriptive of sign-users' learning possibilities. Such holistic views on language, where instances of linguistic performance ('parole', to use a Saussurean term) are restricted by the language (Saussure's 'langue') itself, suppose little (if at all) semiotic freedom from behalf of the users. According to Kress (2010:28) if language is "regarded as a means fully capable of dealing with all human (rational) meaning" then the resources for meaning-making that language or any such singular and universal mode of representation contain are obscured to its users. Because our environment, as formed by our sense-perception capabilities, is multimodal, resources for modelling are evoked in the inter-relations of (sensory) modes (see Kress 2010: 27-28). This is because semiotic tools, such as sensory-motor possibilities, the

5 For instance, an interesting research avenue that semiotics seized is the criticism of institutionalized conventions on teaching and learning, such as, among others, the construal of 'student ability' (Stables et al. 2018). 
various sense perception channels, cognition, co-evolved together. This hypothesis is eagerly embraced in biosemiotics (from Damasio 1994, and mostly starting with Deacon 1997; see Cobley 2016: 56) and particularly in its approaches to the body (Hoffmeyer 2008: 179) and language evolution (Scalia 2019, see above). Thus, capabilities of discovering resources for meaning are, to begin with, multimodal and, therefore, the resources themselves are multimodal as according to the specific umwelt. In this case, competences for discovering meaning, whatever they might be, have to be thought of in relation to semiotic resources. Following Kress' reasoning (e.g. 2003, 2010) this points out to the need of a multimodal semiotic rather than a linguistic monomodal construal of meaning making. This justifies Cobley's argument for developing cultural criticism (and not only) in terms of modelling (Cobley 2016, see above).

In a secondary language teaching purpose, attempting to overcome the rigidity of teaching methods supposed by the assumption that verbal fluency depends on communicative or linguistic competencies, Danesi (2000: 43) argues in favour of a notion of semiotic competence as stemming from cognitive linguistics. Drawing on the conceptual metaphor theory of Lakoff and Johnson ${ }^{6}(1980,1999)$ and on Langacker's $(1987,1990)$ cognitive approach to grammar, Danesi (2000: 42) defines semiotic competence as "the ability to interrelate the underlying structure of concepts to the surface grammar and vocabulary that reflects them". This is a more learner-centred, rather than language-centred, perspective on competence, admitting a higher degree of subjectivity and, implicitly, a higher degree of freedom in sign-use. Danesi considers not only that the framework of cognitive linguistics, with its awareness of cognition as embodied, is properly semiotic, but also that, unlike previous notions of linguistic and semiotic competence, "it has provided the theoretical coordinates for investigating semiotic competence in terms of its educational implications" (Danesi 2000: 43). However, it might still limit modelling and cognitive competences as relative to a top-down, normative imposition of sign systems upon sign-users. According to Danesi (2000: 14), "the ability to interconnect verbal and conceptual structures in speech" is sought in "culturallyappropriate ways". While inspired by pioneering research on embodied cognition and admittedly not discussing learning beyond the scope of secondary language acquisition, this account also subjects semiotic competence to a nature/culture dichotomy by not fully considering the role of the body in language learning. For instance, Danesi (2000: 23) also argues that body language constitutes a "cultural grammar", emphasizing the culture-specific role of the body and the variations of

6 Kress argues that his social semiotic theory of multimodal communication rests as well on Lakoff and Johnson's conceptual metaphor theory (see Kress 2010: 55). 
body concepts across cultures. This makes Danesi's argument a target of Stjernfelt's criticism of the tradition in semiotics that regards the body as a language- or culture-dependent concept much more than acknowledging the body as the essential prerequisite for the possibility of meaning articulation. Consequently, it does not take into consideration that semiotic competences stem from the body's morphology (Stjernfelt 2006, see above). Nevertheless, in Danesi's approach to language education, the acquisition of verbal skills is seen as connected to body language (Danesi 2000: 22). This already supposes a multimodal dimension of language, which thus consists in more than merely a lexicon and some rules. It is also worth noting that in other places Danesi takes a more embodied and modelling-centred approach to knowledge (e.g. Sebeok, Danesi 2000; Danesi 2003).

Drawing on Merleau-Ponty's (1995) phenomenology of the body, Stjernfelt claims that semiotic competence, the organism's capabilities of making sense of the environment, starts with the body's morphology. In a subtle argumentation, Hoffmeyer (2008) stresses the critical role that the skin has for any human's sense of self. The skin is the organ that simultaneously encapsulates the body and opens it up to the outer world:

The semiotics of the skin encompasses numerous other elements beyond those associated with the senses of feeling and pain. Generally, the skin might be considered a user interface that couples us to the outer world. On one hand, the skin thus serves us as a kind of topological boundary; while, on the other hand, its semiotic capacity opens up the world to us - so that the question of where our 'self' begins and ends is not at all an easy question to answer scientifically. (Hoffmeyer 2008: 173)

Moreover, Hoffmeyer (2008: 172) locates (the origin) of personhood in the skin:

[...] it is the skin that tells us about the person we are, as well as about the people (and the world) that we are facing: color, form, energy, and smell provide a constant barrage of information exchange for and among humans, across the interface that is the skin.

This embodied understanding of self and personhood has profound consequences for conceptualizing learning. First of all, all animals that are wrapped up in skin start to learn about their place in the world through their skin. This already places learning on the same evolutionary spectrum with adaptive and exaptive processes. Also, most importantly, such a concept frames learning as implicitly environmental: all learning, as it were, passes through the skin. It consists in loops of both 
exosemiosis and endosemiosis: what happens outside the boundaries of the skin is perceived and processed within those boundaries, leading to behavioural decisions that result in change for both the individual organism and the environment. This does not imply a cybernetic concept of the body and environment, where the body simply receives inputs from and sends back outputs to an outer environment. Exosemiosis and endosemiosis proceed together, in a relation of complementarity, as made possible but also restricted by that morphology which, in the case of complex organisms that have this organ, is wrapped in skin. This idea is present in von Uexküll's theoretical biology. From the way in which Uexküll defined his concept of umwelt, the idea of the co-evolution of organisms and environmental factors is already implied:

Every animal is a subject, which, in virtue of the structure peculiar to it, selects [or chooses $]^{7}$ stimuli from the general influences of the outer world, and to these it responds in a certain way. These responses, in their turn, consist of certain effects on the outer world, and these again influence the stimuli. In this way there arises a self-contained periodic cycle, which we may call the function-circle of the animal. (Uexküll 1926: 126)

In view of this, Nöth (1998: 339) remarks that "Umwelt and the inner world [...] constitute[s] a hermeneutic circle", thus revealing one of the most impressive and critical contributions that (contemporary) semiotics has to offer to current theories of epistemology, ecology and learning: it accounts for the interpretative dimension of embodiment (see also Levesque's 2016 proposal of semiotics as supportive of ecosophy). This is to claim, with Stables (2012: 46, see above) that what limits learning coincides with what opens up learning possibilities. This plasticity starts with the skin. That the animal can select (or choose) elements from the outer world for semiosic modelling means that the landscape presents to the animal objects that, in a first phenomenological instance, have a certain neutrality:

[...] the perception of neutral objects is, of course, a prerequisite to learning because learning in some sense consists of nothing but the de-neutralization of neutral objects, drawing them into segments of functional circles. In order to be thus invested with meaning, neutral objects, of course, must be phenomenologically presented before learning. The perfect fit between organism and environment must thus be relativized: life time adaptability presupposes to some degree the perception of neutral objects which are not immediately functionally relevant. (Stjernfelt 2006: 23-24)

7 Kalevi Kull suggested this nuance of translation to the authors. 


\section{Concluding}

We have argued that a simple distinction between Darwinian adaptation and humanist/modernist conceptions of learning is reductive and grounded in Cartesian dualism. A conception of semiotic modelling, drawing on Sebeok among others, allows us to acknowledge that not all learning is conscious (see also Hoffmeyer, Stjernfelt 2016), that long-term genetic change may result from shorter-term epigenetics and tool use, and that exaptation can provide rich evolutionary resources, and may ultimately be inseparable from adaptation. As such, our argument supports the biosemiotic redefinition of the neoconstructivist notion of scaffolding and, further on, the investigation of learning and education in view of the semiosic continuity of the environment that this involves. Considering all this, an account of learning emerges which is ecological and environmental rather than purely cognitive, rational and individual, and an account of adaptation emerges that comprises more than merely long-term observable physical species changes. This semiotic account, we consider, is compatible and complementary with other theories that bear on both learning and the environment, such as Gibson's affordance theory (e.g., Gibson 1986, 2014 [1979]) Polanyi's theory of knowledge (e.g., Polany 1946) and Bateson's ecology of mind (Bateson 1972). ${ }^{8}$

\section{References}

Akamatsu, Tsutom 2009. André Martinet's contribution to phonology and its legacy. La linguistique 1(45): 61-73.

Baldwin, James Mark 1896. A new factor in evolution. American Naturalist 30: 441-451, 536553.

Barnett, Ronald 1994. The Limits of Competence: Knowledge, Higher Education and Society. Buckingham: Open University Press.

Bateson, Gregory 1972. Steps to an Ecology of Mind. Chicago: University of Chicago Press. Boas, Franz 1938[1911]. The Mind of Primitive Man. New York: The Macmillan Company. Benedict, Ruth 1934. Patterns of Culture. Boston, New York: Houghton Mifflin Company. Bruner, Jerome S. 1957. Going beyond the Information Given. New York: Norton.

- 1966. Toward a Theory of Instruction. Cambridge: Belknap.

- 1999[1960]. The Process of Education. (25th ed.) Cambridge: Harvard University Press. Chomsky, Noam 1965. Aspects of the Theory of Syntax. Cambridge: MIT Press.

Cobley, Paul 2010. The cultural implications of biosemiotics. Biosemiotics 3: 225-244.

- 2016. Cultural Implications of Biosemiotics. Dordrecht: Springer

8 Acknowledgements: The research for this article was supported by the research grant MOBJD346 "Towards a joint environmental and digital literacy: An ecosemiotic approach to digitalization", which Alin Olteanu receives from the Estonian Research Council. 
- 2017. What the humanities are for - a semiotic perspective. In: Bankov, Kristian; Cobley, Paul (eds.), Semiotics and Its Masters. Berlin: Mouton de Gruyter, 3-23.

CP = Peirce, Charles Sanders. The Collected Papers of Charles Sanders Peirce. (Hartshorne, Charles; Weiss, Paul, eds. 1931-1935; Burks, Arthur W., ed. 1958.) Cambridge: Belknap. [In-text references are to $\mathrm{CP}$, followed by volume and paragraph numbers.]

Crutzen, Paul J.; Stoermer, Eugene F. 2000. The Anthropocene. Global Change Newsletter 41: $17-18$.

Culler, Jonathan 1980. Literary competence. In: Tompkins, Jane P. (ed.), Reader-Response Criticism: From Formalism to Post-Structuralism. Baltimore, London: Johns Hopkins University Press, 101-117.

Damasio, Antonio 1994. Descartes' Error: Emotion, Reason, and the Human Brain. New York: Putnam Books.

Danesi, Marcel 2000. Semiotics in Language Education. Berlin, New York: Mouton de Gruyter.

- 2003. Metaphorical "networks" and verbal communication: A semiotic perspective of human discourse. Sign Systems Studies 31(2): 341-364.

Darwin, Charles 2008[1859]. On the Origin of Species. Oxford: OUP.

Deacon, Terrence 1997. The Symbolic Species: The Co-Evolution of Language and the Brain. London, New York: W. W. Norton \& Co.

Deely, John 2001. Four Ages of Understanding: The First Postmodern Survey of Philosophy from Ancient Times to the Turn of the Twenty-First Century. Toronto: University of Toronto Press.

Deleuze, Gilles; Guattari, Félix 1987[1980]. A Thousand Plateaus: Capitalism and Schizophrenia. (Massumi, Brian, trans.) Minneapolis, London: University of Minnesota Press.

Dennett, Daniel C. 1996. Darwin's Dangerous Idea. New York: Simon \& Schuster.

Derrida, Jacques 1978[1967]. Writing and Difference. (Bass, Alan, ed.) London: Routledge.

- 1981. Positions. (Bass, Alan, trans.) Chicago: The University of Chicago Press.

Eco, Umberto 1976. A Theory of Semiotics. Bloomington: Indiana University Press.

Elleström, Lars 2018. A medium-centered model of communication. Semiotica 224: 269-293.

- 2019. Modelling human communication: Mediality and semiotics. In: Olteanu, Alin; Stables, Andrew; Borțun, Dumitru (eds.), Meanings \& Co.: The Interdisciplinarity of Semiotics, Communication and Multimodality. Cham: Springer, 7-32.

Eriksen, Jens-Martin; Stjernfelt, Frederik 2010. Culturalism - from idea to unconscious presupposition. Sociologija 52(4): 359-376.

- 2012. The Democratic Contradictions of Multiculturalism. New York: Telos Press.

Favareau, Donald (ed.) 2010a. Essential Readings in Biosemiotics: Anthology and Commentary. Dordrecht: Springer.

- 2010b. Introduction: An evolutionary history of biosemiotics. In: Favareau, Donald (ed.), Essential Readings in Biosemiotics. Dordrecht: Springer, 1-77.

Gibson, James J. 1986. The Ecological Approach to Visual Perception. New York: Cornell University Press.

- 2014[1979]. The theory of affordances. In: Gieseking, Jen Jack; Mangold, William; Katz, Cindi; Low, Setha; Saegert, Susan (eds)., The People, Place, and Space Reader. New York: Routledge, 56-61.

Gough, Steven; Stables, Andrew 2012. Interpretation as adaptation education for survival in uncertain times. Curriculum Inquiry 42(3): 368-385.

Gould, Stephen J., Vrba, Elisabeth S. 1982. Exaptation - a missing term in the science of form. Paleobiology 8(1): 4-15. 
Greimas, Algirdas Julian; Courtés, Joseph 1982[1979]. Semiotics and Language: An Analytical Dictionary. Bloomington: Indiana University Press.

Hoffmeyer, Jesper 2006. Semiotic scaffolding of living systems. In: Barbieri, Marcello (ed.), Introduction to Biosemiotics: The New Biological Synthesis, 149-166.

- 2008. The biosemiotic body. Biosemiotics 1: 169-190.

- 2014. The semiome: From genetic to semiotic scaffolding. Semiotica 198: 11-31.

- 2015. Semiotic scaffolding of multicellularity. Biosemiotics 8(2): 159-171.

Hoffmeyer, Jesper; Stjernfelt, Frederik 2016. The Great Chain of Semiosis: Investigating the steps in the evolution of semiotic competence. Biosemiotics 9: 7-29.

Hoffmeyer, Jesper; Kull, Kalevi 2003. Baldwin and biosemiotics: What intelligence is for. In: Weber, Bruce H.; Depew, David J. (eds.), Evolution and Learning: The Baldwin Effect Reconsidered. Cambridge; London: The MIT Press, 253-272.

Kleisner, Karel 2015. Semantic organs: The concept and its theoretical ramifications. Biosemiotics 8(3): 367-379.

Kress, Gunther 2003. Literacy in the New Media Age. London, New York: Routledge.

- 2010. Multimodality: A Social Semiotic Approach to Contemporary Communication. London, New York: Routledge.

Kull, Kalevi 2015. Evolution, choice, and scaffolding: Semiosis is changing its own building. Biosemiotics 8: 223-234.

Langer, Susanne 1957[1941]. Philosophy in a New Key: A Study in the Symbolism of Reason, Rite, and Art. (3rd ed.) London, Cambridge: Harvard University Press.

Lakoff, George; Johnson, Mark 1980. Conceptual metaphor theory in everyday language. The Journal of Philosophy 77(8): 453-486.

- 1999. Philosophy in the Flesh: The Embodied Mind and its Challenge to Western Thought. New York: Basic Books.

Langacker, Ronald W. 1987. Foundations of Cognitive Grammar: Theoretical Prerequisites. Stanford: Stanford University Press.

- 1990. Concept, Image, and Symbol: The Cognitive Basis of Grammar. Berlin, New York: Mouton de Gruyter.

Lestel, Dominique 2011[2002]. The biosemiotics and phylogenesis of culture. In: Maran, Timo; Martinelli, Dario; Turovski, Aleksei (eds.), Readings in Zoosemiotics. Berlin: De Gruyter Mouton, 377-409.

Levesque, Simon. 2016. Two versions of ecosophy: Arne Næss, Félix Guattari, and their connection with semiotics. Sign Systems Studies 44(4): 511-541.

Lotman, Juri 1977. Primary and secondary communication-modeling systems. In: Lucid, Daniel Peri (ed.), Soviet Semiotics: An Anthology. Baltimore: Johns Hopkins University Press, 95-98.

- 1990. Universe of the Mind. (Shukman, Ann, trans.; Eco, Umberto, intr.) London: I. B. Tauris.

MacLarnon, Ann 2012. The anatomical and physiological basis of human speech production: Adaptations and exaptations. In: Gibson, Kathleen R.; Tallerman, Maggie (eds.), The Oxford Handbook of Language Evolution. Oxford: Oxford University Press, 224-235.

Martinelli, Dario 2010. A Critical Companion to Zoosemiotics: Peoples, Paths, Ideas. Dordrecht: Springer.

- 2016. Arts and Humanities in Progress: A Manifesto of Numanities. Cham: Springer. Martinet, André 1962. A Functional View of Language. Oxford: Oxford University Press. Merleau-Ponty, Marcel 1995. La Nature. Notes. Cours de Collège de France. Paris: Seuil. 
Mulder, Martin; Gulikers, Judith; Biemans, Harm; Wesselink, Renate 2009. The new competence concept in higher education: Error or enrichment? Journal of European Industrial Training 33: 755-770.

Nussbaum, Martha 2010. Not for Profit - Why Democracy Needs the Humanities. Princeton: Princeton University Press.

Nöth, Winfried 1995. Handbook of Semiotics. Bloomington, Indianapolis: Indiana University Press.

Olteanu, Alin 2015. Philosophy of Education in the Semiotics of Charles Peirce: A Cosmology of Learning and Loving. Oxford: Peter Lang.

- 2018. Semiotics as a Proposal for a Numanistic Educational Programme. In: Andreică, Oana; Olteanu, Alin (eds.), Readings in Numanities. Cham: Springer, 3-17.

Olteanu, Alin; Campbell, Cary 2018. A short introduction to edusemiotics. Chinese Semiotic Studies 14(2): 245-260.

Olteanu Alin; Kambouri-Danos, Maria; Stables, Andrew 2016. Predicating from an early age: Edusemiotics and the potential of children's preconceptions. Studies in Philosophy and Education 35(6): 621-640.

Pelkey, Jamin 2017. The Semiotics of X: Chiasmus, Cognition, and Extreme Body Memory. New York: Bloomsbury.

Pikkarainen, Eetu 2014. Competence as a key concept of educational theory: A semiotic point of view. Journal of Philosophy of Education 48(4): 621-636.

Polanyi, Michael 1964. Man's home in the universe. Bulletin of the American Academy of Arts and Sciences 17(8): 3-6.

Randviir, Anti; Cobley. Paul 2010. Sociosemiotics. In: Cobley, Paul (ed.), The Routledge Companion to Semiotics. New York: Routledge, 118-134.

Rockström, Johan; Steffen, Will, Noone, Kevin; Persson, Åsa; Chapin, F. Stuart; Lambin, Eric F.; Lenton, Timothy M.; Scheffer, Marten; Folke, Carl; Schellnhuber, Hans Joachim; Nykvist, Björn; De Wit, Cynthia A. D.; Hughes, Terry; Van der Leeuw, Sander; Rodhe, Henning; Sörlin, Sverker; Snyder, Peter K.; Costanza, Robert; Svedin, Uno; Falkenmark, Malin; Karlberg, Louise; Corell, Robert W.; Fabry, Victoria J.; Hansen, James; Walker, Brian; Liverman, Diana; Richardson, Katherine; Crutzen, Paul; Foley, Jonathan A. 2009. Planetary boundaries: Exploring the safe operating space for humanity. Ecology and Society 14(2): 32.

Saussure, Ferdinand de 1959[1916]. Course in General Linguistics. (Bally, Charles; Sechehaye, Albert, eds.; Baskin, Wade, trans.) New York, Toronto, London: McGraw-Hill.

Scalia, Jeremiah Cassar 2019. Towards a holo-semiotic framework for the evolution of language. In: Olteanu, Alin; Stables, Andrew; Borțun, Dumitru (eds.), Meanings \& Co.: The Interdisciplinarity of Semiotics, Communication and Multimodality. Cham: Springer, 89-104.

Sebeok, Thomas A. 1985. Zoosemiotic components of communication. In: Innis, Robert E. (ed.), Semiotics: An Introductory Anthology, 294-318. Indiana: Indiana University Press.

- 1986. I Think I Am a Verb: More Contributions to the Doctrine of Signs. New York: Springer.

- 1991. A Sign Is Just a Sign: Advances in Semiotics. Bloomington, Indianapolis: Indiana University Press.

- 2001a[1994]. Signs: An Introduction to Semiotics. Toronto: University of Toronto Press.

- 2001b. Nonverbal communication. In: Cobley, Paul (ed.), The Routledge Companion to Semiotics and Linguistics. New York: Routledge, 14-27. 
Sebeok, Thomas; Danesi, Marcel 2000. The Forms of Meaning: Modelling Systems Theory and Semiotic Analysis. Berlin, New York: Mouton de Gruyter.

Semetsky, Inna (ed.) 2010. Semiotics, Education, Experience. Rotterdam: Sense Publishers.

Sharov, Alexei; Maran, Timo; Tønnessen, Morten 2015. Organisms reshape sign relations. Biosemiotics 8: 361-365.

- 2016. Comprehending the semiosis of evolution. Biosemiotics 9(1): 1-6.

Stables, Andrew. 2012. Be(com)ing Human: Semiosis and the Myth of Reason. Rotterdam: Sense Publishers.

Stables, Andrew; Gellard, Claire; Cox, Sarah 2018. Teachers' conceptions of students' 'ability':

Creating the space for professional judgment. Pedagogy, Culture \& Society 26.

Stables, Andrew; Semetsky, Inna 2015. Edusemiotics: Semiotic Philosophy as Educational

Foundation. New York: Routledge.

Steffen, Will; Persson, Åsa; Deutsch, Lisa; Zalasiewicz, Jan; Williams, Mark; Richardson,

Katherine; Crumley, Carole; Crutzen, Paul; Folke, Carl; Gordon, Line; Molina, Mario;

Ramanathan, Veebrabhadran; Rockström, Johan; Scheffer, Marten; Schellnhuber, Hans Joachim; Svedin, Uno 2011. The anthropocene: From global change to planetary stewardship. AMBIO 40: 739-761.

Stjernfelt, Frederik 2006. The semiotic body. A semiotic concept of embodiment? In: Nöth,

Winfried (ed.), Semiotic Bodies, Aesthetic Embodiments and Cyberbodies. Kassel: Kassel University Press, $13-48$.

- 2011. What is culturalism? - The anatomy of a contemporary disease in academia and politics. Lexia. Rivista Semiotica 5-6: 369-400.

- 2012. The evolution of semiotic self-control. In: Schilhab, Theresa; Stjernfelt, Frederik;

Deacon, Terrence (eds.), The Symbolic Species Evolved. Dordrecht: Springer, 39-63.

- 2014. Natural Propositions: The Actuality of Peirce's Doctrine of Dicisigns. Boston: Docent Press.

- 2015. Dicisigns: Peirce’s semiotic doctrine of propositions. Synthese 192: 1019-1054.

Uexküll, Jakob von 1926. Theoretical Biology. London: Kegan Paul, Trench, Trubner \& Co.

- 2010[1934, 1940]. A Foray into the Worlds of Animals and Humans with a Theory of Meaning. Minneapolis: University of Minnesota Press.

Vygotsky, Lev Semenovich 1978. Mind in Society: The Development of Higher Psychological Processes. Cambridge, London: Harvard University Press.

Westera, Wim 2001. Competence in education: A confusion of tongues. Journal of Curriculum Studies 33: 75-88.

\section{Обучение и адаптация с семиотической точки зрения}

Данная статья рассматривает связь между обучением и адаптацией, утверждая, что новейшие разработки в семиотике указывают на отсутствие разрыва между ними. Обзор соответствующих теорий в этой области выявляет подход к обучению, связанный с вживанием и средой, где язык играет важную, но все же ограниченную роль. Обучение и адаптация рассматриваются как неотделимые случаи семиотического моделирования. Подобное конструирование этих явлений открывает новые пути в сторону недуалистической философии и теории образования. 


\section{Alin Olteanu, Andrew Stables}

\section{Õppimine ja adapteerumine semiootilisest vaatekohast}

Artiklis vaadeldakse õppimise ja adapteerumise omavahelist suhet, väites, et semiootika uusimad seisukohad osutavad katkestuse puudumisele nende kahe nähtuse vahel. Ülevaade valdkonna suhtes olulistest teooriatest toob semiootika poolt vaadatuna esile kehastumuse (embodiment) ja keskkonnaga seotud arusaama õppimisest, milles keel mängib küll olulist, ent siiski piiratud osa. Õppimist ja adapteerumist vaadatakse semiootilise modelleerimise lahutamatute juhtumitena. Nende nähtuste seesugune konstrueerimine avab uusi arenguteid mittedualistliku filosoofia ja haridusteooria suunas. 